\title{
Macrophage migration inhibitory factor: a potential therapeutic target for rheumatoid arthritis
}

\author{
Kyoung-Woon $\mathrm{Kim}^{1}$ and Hae-Rim $\mathrm{Kim}^{2}$
}

\begin{abstract}
${ }^{1}$ Convergent Research Consortium for Immunologic Disease, College of Medicine, Seoul St. Mary's Hospital, The Catholic University of Korea, Seoul; ²Division of Rheumatology, Department of Internal Medicine, Research Institute of Medical Science, Konkuk University School of Medicine, Seoul, Korea
\end{abstract}

Received: April 7, 2016

Accepted: April 26, 2016

\section{Correspondence to}

Hae-Rim Kim, M.D.

Division of Rheumatology,

Department of Internal

Medicine, Konkuk University

School of Medicine, 120-1

Neungdong-ro, Gwangjin-gu,

Seoul 05030, Korea

Tel: +82-2-2030-7542

Fax: +82-2-2030-7748

E-mail: kimhaerim@kuh.ac.kr
Macrophage migration inhibitory factor (MIF) is originally identified in the culture medium of activated $\mathrm{T}$ lymphocytes as a soluble factor that inhibits the random migration of macrophages. MIF is now recognized as a multipotent cytokine involved in the regulation of immune and inflammatory responses. In rheumatoid arthritis (RA), MIF promotes inflammatory responses by inducing proinflammatory cytokines and tissue-degrading molecules, promoting the proliferation and survival of synovial fibroblasts, stimulating neutrophil chemotaxis, and regulating angiogenesis and osteoclast differentiation. Expression of MIF in synovial tissue and synovial fluid levels of MIF are elevated in RA patients. Specifically, MIF levels correlate with RA disease activity and high levels are associated with bone erosion. In animal models of RA, the genetic and therapeutic inhibition of MIF has been shown to control inflammation and bone destruction. Based on the role of MIF in RA pathogenesis, small molecular inhibitors targeting it or its receptor pathways could provide a new therapeutic option for RA patients.

Keywords: Macrophage migration-inhibitory factors; Arthritis, rheumatoid; Inflammation; Small molecular inhibitor

\section{INTRODUCTION}

Rheumatoid arthritis (RA) is a chronic and debilitating autoimmune disease characterized by the interaction of various inflammatory mediators and cells [1]. Although the etiology of RA is not clear, inflammatory cytokines and tissue-destructive molecules play key roles in the initiation and progression of the inflammatory processes that characterize the disease [2]. Accordingly, biological agents that inhibit proinflammatory cytokines have been widely used in the treatment of RA [3].

Macrophage migration inhibitory factor (MIF) is an evolutionarily ancient and highly conserved cytokine that was originally described as an activity of cognate $\mathrm{T}$ cell supernatants that inhibits macrophage migration [4]. MIF is cloned and purified, and its activity character- ized at the molecular level in 1993 [5]. MIF is structurally unique; it has a monomeric molecular mass of $12.5 \mathrm{kDa}$ and consists of two antiparallel $\alpha$-helices that together with six $\beta$-pleated sheets form the extended secondary structure of the molecule. Biophysical studies indicate that, in its active form, MIF is a homotrimeric molecule with topological homology to only one other mammalian protein, the enzyme d-dopachrome tautomerase [6], a broad-spectrum intra- and extracellular protein produced by a variety of cell types, including monocytes/ macrophages [7], lymphocytes [8], eosinophils [9], neutrophils [10], epithelial cells [11,12], endothelial cells [13], and smooth muscle cells [14]. By contrast, MIF has a chemokine-like function, promoting the migration and recruitment of leukocytes to infectious and inflammatory sites $[15]$. 
MIF is stored in pre-formed cytoplasmic pools and is rapidly released in response to stimuli such as microbial products, proliferative signals, and hypoxia [7,16,17]. One of the earliest physiological functions described for MIF was as a counter-regulator of glucocorticoid-mediated suppression of immune cell responses [18], which is important for the regulation of systemic inflammatory responses in settings such as invasive stress or acute illness, characterized by high adrenal glucocorticoid levels. MIF also plays a pivotal upstream role in sustaining immune cell survival, by inhibiting activation-induced apoptosis. This effect serves to provide for optimal but, in some pathologic circumstances, excessive, inflammatory responses [19].

MIF participates in the pathogenesis of many inflammatory diseases, including colitis [20], multiple sclerosis [21,22], systemic lupus erythematosus [23,24], glomerulonephritis [25,26], psoriasis [27,28], and diseases more recently recognized as inflammatory, such as atheroma formation and even atheromatous plaque rupture.

\section{MIF IN THE PATHOGENESIS OF RA}

Expression of MIF is increased in the arthritic joints of patients with juvenile idiopathic arthritis and in those with RA [29-31]. Serum and synovial fluid levels of MIF are also higher in RA patients than in either osteoarthritis patients or healthy volunteers. These high levels are associated with bone erosion and disease activity [26,32-34].

MIF stimulates the release of tumor necrosis factor (TNFF), interleukin IL-1, IL-6, IL-8, and prostaglandin from macrophages and synovial fibroblasts to induce matrix metalloproteinase (MMP)-1 and MMP-3, phospholipase $\mathrm{A} 2$, and cyclooxygenase-2, which together lead to tissue degradation in RA-related processes [35]. MIF also induces MMP-9 and MMP-13 in rat osteoblasts, which may be relevant to the bone destruction and osteoporosis characteristic of RA [36]. Tissue degradation by MMPs is a typical pathological feature of RA. MIF contributes to this process by up-regulating MMP-1 and MMP-3 mRNA levels in synovial fibroblasts, which in large part are responsible for the degradation of extracellular matrix components in RA (Fig. 1) [35]. The up-regulation of MMP genes by MIF is probably mediated by a complex regulatory system. Glucocorti- coids repress MMP-1 gene transcription via the interaction of glucocorticoid receptor proteins with the activator protein (AP)-1 complex [37]. The interaction of MIF and glucocorticoid/AP-1 was reported by Chauchereau and coworkers [38], who showed that Jun activation domain-binding protein-1 (Jab1)/CSN 5 COP9 signalosome subunit 5 (CSN5) binds to the glucocorticoid receptor. Together, these studies demonstrated the potent counter-regulatory activity of MIF in the glucocorticoid-mediated control of inflammation in general [39] and synovial inflammation in particular [40].

MIF induces proliferation of human RA synovial fibroblasts and inhibits both p53 expression and apoptosis [41,42]. Accordingly, MIF inhibition would convey a proapoptotic signal to these hyperplastic cells.

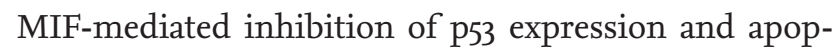
tosis prolongs cell survival and has been described in macrophages [19]. MIF also interacts closely with various

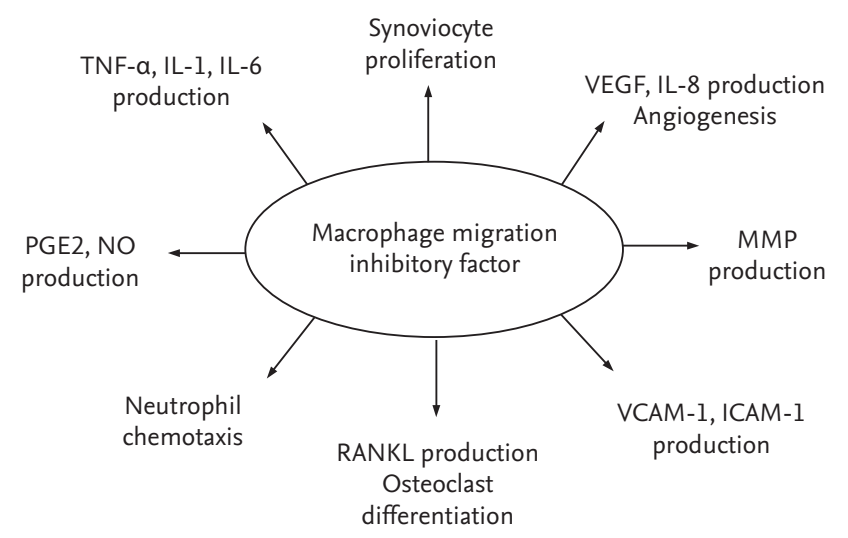

Figure 1. The role of macrophage migration inhibitory factor (MIF) in the pathogenesis of rheumatoid arthritis (RA). MIF stimulates the release of tumor necrosis factor (TNF)- $\alpha$, interleukin (IL)-1, IL-6, IL-8, and prostaglandin from macrophages and synovial fibroblasts to induce matrix metalloproteinase (MMP)-1 and MMP-3, phospholipase A2, cyclooxygenase-2, which in RA patients may lead to tissue degradation. MIF also induces MMP- 9 and MMP13 in rat osteoblasts; a similar response may account for the bone destruction and osteoporosis characteristic of RA. MIF induces the production of vascular endothelial growth factor (VEGF) and IL-8 from synovial fibroblasts as well as endothelial tube formation. It also stimulates receptor activator of nuclear factor $\mathrm{kB}$ ligand (RANKL) production by RA synovial fibroblasts and causes differentiation of peripheral blood monocytes to mature osteoclasts. PGE2, prostaglandin E2; NO, nitric oxide; VCAM, vascular cell adhesion molecule; ICAM, intercellular adhesion molecule. 
proinflammatory cytokines and plays a major role in innate immunity against bacterial infections, by enhancing TNF- $\alpha$ secretion [5], Toll-like receptor 4 expression [43], phagocytosis, and intracellular killing mechanisms [44]. In addition, it is equally efficiently involved in the adaptive immune response, by favoring Thr activation and differentiation. The autocrine and paracrine effects of MIF on immune cell activation include the induction of IL-1 and TNF, which in turn stimulate further MIF production $[18,45]$. Endogenous MIF is required for IL1- and TNF-induced mitogen-activated protein kinase (MAPK) activation and regulates the expression of the receptors for these cytokines [46].

Anti-TNF therapy in RA patients diminishes the serum levels of the chemokine chemerin, a specific chemoattractant for macrophages and dendritic cells. The suppression of these MIF-producing cells decreases serum MIF concentrations, which in turn reduces inflammation [47]. The arthritic joints in MIF-mice have lower serum IL-1 $\beta$ and IL- 6 levels, but the levels of these cytokines are restored when the defect in these mice is reconstituted using wild-type macrophages.

Vascular endothelial cells play vital roles in systemic inflammatory and immunological events; for example, the cytokines and growth factors produced by endothelial cells participate in complex inflammatory processes [48]. MIF mRNA is not limited to T lymphocytes or macrophages but is also expressed in vascular endothelial cells. In RA patients, serum and synovial fluid MIF levels correlate with vascular endothelial growth factor (VEGF) levels. MIF stimulates synovial fibroblasts to produce VEGF and IL-8; in vitro, it stimulates human umbilical vein endothelial cells to increase vascular tube formation [49]. Endothelial cells also readily secrete their cytoplasmic stores of MIF in response to the presence of a bacterial component, such as in infectious states. MIF subsequently initiates production of the proinflammatory cytokines TNF- $\alpha$ and IL-1. Thus, MIF is not only an initiator of the inflammatory process involving endothelial cells but also acts as a growth factor in the response to cellular damage.

Although the data are controversial, an osteoclastogenic role for MIF in human RA has been reported. MIF stimulates both the production of receptor activator of nuclear factor $\mathrm{kB}$ ligand (RANKL) by RA synovial fibroblasts and the differentiation of peripheral blood monocytes to mature osteoclasts [50]. MIF-triggered RANKL expression is partially reduced by blockage of IL-1 $\beta$, while osteoclastogenesis is suppressed by inhibition of nuclear factor- $\mathrm{KB}(\mathrm{NF}-\kappa \mathrm{B})$, phosphatidylinositol 3-kinase ( $\left.\mathrm{PI}_{3} \mathrm{~K}\right), \mathrm{p}_{3} 8 \mathrm{MAPK}$, and AP-1. Other studies have also shown that MIF significantly up-regulates MMP-13 mRNA expression in rat primary osteoblasts, by activating Src-related tyrosine kinase, extracellular signal regulated kinase (ERK) $1 / 2$, and AP-1-dependent signaling pathways [36]. Collectively, these results support a role for MIF as an upstream regulator of synovial cytokine expression in RA.

An association of MIF polymorphisms with RA has been described in a number of studies. In their study of a Chinese population, Liu et al. [51] reported that the MIF-173 C allele, in which there is an alteration in the MIF promoter region, may contribute to RA susceptibility and increase the risk of RA. Similarly, an association between the -794 CATT7 7 and $-173{ }^{*} \mathrm{C}$ alleles, which are in linkage disequilibrium, and the high clinical activity of RA has been reported [52]. Thus, MIF polymorphisms may be associated with both a higher risk and a greater severity of RA.

\section{Intracellular signal pathways of MIF}

The signal transduction pathways used by MIF in its activation of cells and cellular events is incompletely defined, although cell-surface-receptor-mediated pathways have been implicated (Fig. 2) [53]. Recently, CD74, the cell surface form of the class II invariant chain, was identified as the receptor for MIF [54]. The interaction of MIF with $\mathrm{CD}_{74}$ activates MAPK pathways [53], and the phosphorylation of MAPKs leads to the expression of target genes that are important in inflammation and proliferation. These observations highlight the importance of MAPKs in RA [55]. The activation of distinct MAPK subtype cascades is dependent on the cell type and the nature of the stimuli used; furthermore, the functional role of each MAPK may differ depending on the cell type. In general, the ERK cascade mediates the proliferation, differentiation, and survival of signal-promoting cells, whereas both p38 and JNK MAPKs are involved in cell responses to environmental stresses and inflammatory cytokines [55,56]. MIF-induced ERK activation is associated with cell proliferation and prostaglandin E2 production [53]. This is in keeping with the 


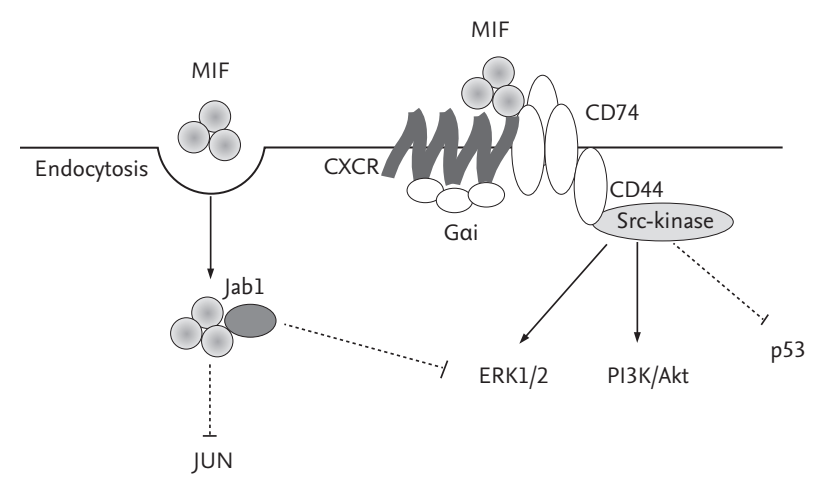

Figure 2. Signal pathways of migration inhibitory factor (MIF). MIF is induced in response to cytokine production and, after its endocytosis, can interact with intracellular proteins such as Jun activation domain-binding protein-1 (Jabı), thereby down-regulating mitogen-activated protein kinase (MAPK) signals and modulating cellular redox homeostasis. Extracellular MIF binds to the cell surface protein $\mathrm{CD}_{74}$ (invariant chain Ii). $\mathrm{CD}_{74}$ lacks a signal-transducing intracellular domain but interacts with the proteoglycan $\mathrm{CD}_{44}$, which induce the activation of Src-family kinase and MAPK/extracellular signal-regulated kinase (ERK) pathways to either activate the phosphatidylinositol 3-kinase $\left(\mathrm{PI}_{3} \mathrm{~K}\right) /$ Akt pathway or initiate the p53-dependent inhibition of apoptosis. MIF also can bind and signal through G-protein-coupled chemokine receptors (GPCRs, e.g., CXCR2 and CXCR4) alone. Complex formation between CXCR2 and $\mathrm{CD}_{74}$, enabling accessory binding, appears to facilitate $\mathrm{G}$ protein-coupled receptor (GPCR) activation and the formation of a GPCR-receptor tyrosine kinases like signaling complex to trigger calcium influx and rapid integrin activation.

induction by MIF of a uniquely sustained phosphorylation of ERK [19], associated with increased $\mathrm{NIH} / 3 \mathrm{~T}_{3}$ proliferation and enhanced phospholipase A2 activity. The finding that MIF up-regulation of these cellular events is not accompanied by p3 8 phosphorylation suggests the nonutility of this pathway. Although we demonstrated that MIF induces phosphorylation of $\mathrm{p}_{3} 8$ MAPK in RA synovial fibroblasts [57], the MIF-induced activation and proliferation of synovial fibroblast is mainly mediated by the ERK pathway $[42,57]$. Similarly, MIF phosphorylation of the ERK pathway occurs in the up-regulation of $\mathrm{N}-\mathrm{Myc}$ protein expression in neuroblastoma tissues [58], in the growth and angiogenesis of murine colon cancer cells [59], and in the up-regulation of MMP-1 in human dermal fibroblasts [6o]. The latter study also shows that MIF phosphorylation of the JNK but not the p38 signaling pathway is involved in stimulating MMP-
1 expression [6o]. The MIF-mediated activation of the MAPK pathway is further confirmed in a report showing the activation by MIF of the c-jun element of AP-1 transcription factor in its stimulation of MMP-1 and -3 expression [35,36]. In addition, MIF activates $\mathrm{PI}_{3} \mathrm{~K}$ and its effector kinase, Akt, to promote tumor growth and angiogenesis [59,61]. Clearly, MIF differentially activates distinct signaling pathways to stimulate target cells and cellular events.

The intracellular actions of MIF have also been studied. At high concentrations MIF influences the transcriptional activity of AP-1, by interacting with Jabı [62]. This interaction interrupts AP-1-dependent gene transcription and inhibits the growth-promoting effects of Jabi on fibroblasts. These events demonstrate the contrasting effects of MIF on inflammation and proliferation, which may be related to its relative concentration. Thus, high concentrations of MIF may inhibit AP-1-dependent events to prevent over-activation of the immune response $[53,63,64]$.

\section{THERAPEUTIC EFFECTS OF MIF INHIBITION IN RA ANIMAL MODELS}

A role for MIF in inflammatory joint disease is first explored in the collagen-induced arthritis (CIA) mouse model, which showed that MIF antagonism delays the onset and decreases the frequency of arthritis [65]. MIF promotes Thr immunity and anti-MIF treatment lowers serum immunoglobulin G2a levels, without significant effects on collagen type II-induced interferon- $\gamma$ production. Moreover, the overall T-cell proliferative response to collagen type II is surprisingly higher in anti-MIF-treated mice [65]. Further evidence of a role for MIF in RA comes from two cell-mediated animal models of RA. In rat adjuvant arthritis (AA), anti-MIF therapy dose-dependently reduces disease severity [66]. During disease development, MIF levels are increased in sera and synovial tissue, and an association between synovial MIF and ED1-positive macrophages has been reported [66]. Similarly, MIF antagonism decreases the severity of antigen induced arthritis (AIA) in mice, as measured by synovial hypercellularity, and glucocorticoid treatment impedes disease development [40]. Glucocorticoid regulation of MIF is confirmed in vivo in AA rats [67]. Ad- 
Table 1. Therapeutic effect of MIF inhibition in rheumatoid arthritis animal models

\begin{tabular}{|c|c|c|c|}
\hline Animal model & MIF inhibition & Therapeutic effect & Reference \\
\hline Collagen-induced arthritis & MIF antagonism & Delays onset time, decreases arthritis/lowers IgG2a & {$[65]$} \\
\hline Rat adjuvant arthritis & Anti-MIF & Decreases disease severity & {$[66]$} \\
\hline Antigen-induced arthritis & MIF antagonism & Decreases disease severity (synovial hyper cellularity) & [40] \\
\hline Collagen-induced arthritis & Mif $^{-/}$ & $\begin{array}{l}\text { Suppression of collagen-induced arthritis/reduced } \\
\text { cartilage damage }\end{array}$ & {$[41,68]$} \\
\hline Mif $^{-/-}$ & Mif $^{-/-}$ & Regulation of leukocyte recruitment in the joint & {$[69]$} \\
\hline
\end{tabular}

MIF, migration inhibitory factor; IgG2a, immunoglobulin G2a.

renalectomy prior to AA induction results in increased joint inflammation; in these animals, serum and pituitary MIF levels are increased but, surprisingly, the levels in the synovium are decreased. Nonetheless, MIF regulation of joint inflammation is still significant, as the protective effects of anti-MIF treatment are retained [67]. These findings suggest differential regulation of local and systemic MIF in the context of AA.

Further support for the role of MIF in RA comes from Mif/- mice. Two studies demonstrate suppression of CIA in Mif ${ }^{--}$mice [68]. In the AIA model, Mif/- mice has a reduced severity of histological arthritis, including evidence of reduced cartilage damage [41]. The latter study also shows reduced proliferation of synoviocytes as well as increases in $\mathrm{p}_{53}$ expression and apoptosis in these cells in the absence of MIF (synoviocyte expansion contributes significantly to the development of joint damage in RA by facilitating the invasion of synovium into cartilage and bone). Studies using Mif/- mice also implicates MIF in the regulation of leukocyte recruitment in response to stimuli such as endotoxin and TNF, and directly demonstrated a requirement for MIF in leukocyte recruitment into the joint [69]. These observations suggest that MIF contributes to the hypercellularity of RA synovial lesions through its effects on leukocyte recruitment, proliferation, and survival (Table 1).

MIF may also play a role in the blunted response to steroids. In the study by Santos and coworkers [40], dexamethasone treatment induces inhibition of AIA, whereas MIF treatment reverses the effect of the administered steroid. AIA is significantly inhibited by anti-MIF monoclonal antibodies whereas the synthesis of MIF by synovial cells is enhanced by low concentrations of glucocorticoids.

MIF is a proinflammatory cytokine with a broad range of cellular targets and functions. Other soluble proinflammatory cytokines, such as TNF and IL-1, have been successfully targeted in RA and other inflammatory diseases using bioengineered soluble receptors or receptor antagonists and specific antibodies [70-73]. As a soluble cytokine, MIF and its recently discovered cell surface receptor $\mathrm{CD}_{74}$ suggest the potential of current technologies in targeting MIF in human inflammatory diseases. More importantly, the unique glucocorticoid-antagonistic capability of MIF provides an additional potential target in patients who have become resistant to glucocorticoid therapy during treatment for autoimmune disease. Continued investigation of the molecular immunology of MIF will provide better strategies to target it therapeutically. The success of this approach in RA will include reductions in inflammation, the protection of cartilage and bone, and the favorable reversal of the deficient apoptosis of RA synoviocytes, while leaving NF- $\kappa B$ dependent host defenses intact.

Taken together, these studies recommend further studies of MIF as a potential therapeutic target for RA. However, these must be preceded by elucidation of the role of MIF in RA.

\section{CONCLUSIONS}

The various roles of MIF in the pathogenesis of RA include its promotion of the synthesis of proinflammatory cytokines and tissue-degrading molecules as well as induction of osteoclast differentiation. The inhibition of MIF in animal models of arthritis is proof of the efficient therapeutic effect of this approach in blocking the initiation and progression of arthritis. Small molecular inhibitors that regulate MIF or its signaling pathways 
may provide new therapeutic options for managing RA patients.

\section{Conflict of interest}

No potential conflict of interest relevant to this article was reported.

\section{Acknowledgments}

This research was supported by the Basic Science Research Program, through the National Research Foundation of Korea (NRF), and funded by the Ministry of Education, Science and Technology (2013R1A1A1008171 and 2015R1DiA1A09058510).

\section{REFERENCES}

1. Montecucco F, Mach F. Common inflammatory mediators orchestrate pathophysiological processes in rheumatoid arthritis and atherosclerosis. Rheumatology (Oxford) 2009;48:11-22.

2. Brennan FM, McInnes IB. Evidence that cytokines play a role in rheumatoid arthritis. J Clin Invest 2008;118:35373545 .

3. Burmester GR, Feist E, Dorner T. Emerging cell and cytokine targets in rheumatoid arthritis. Nat Rev Rheumatol 2014;10:77-88.

4. David JR. Delayed hypersensitivity in vitro: its mediation by cell-free substances formed by lymphoid cell-antigen interaction. Proc Natl Acad Sci U S A 1966;56:72-77.

5. Bernhagen J, Calandra T, Mitchell RA, et al. MIF is a pituitary-derived cytokine that potentiates lethal endotoxaemia. Nature 1993;365:756-759.

6. Sun HW, Swope M, Cinquina C, et al. The subunit structure of human macrophage migration inhibitory factor: evidence for a trimer. Protein Eng 1996;9:631-635.

7. Calandra T, Bernhagen J, Mitchell RA, Bucala R. The macrophage is an important and previously unrecognized source of macrophage migration inhibitory factor. J Exp Med 1994;179:1895-1902.

8. Bacher M, Metz CN, Calandra T, et al. An essential regulatory role for macrophage migration inhibitory factor in T-cell activation. Proc Natl Acad Sci U S A 1996;93:78497854 .

9. Rossi AG, Haslett C, Hirani N, et al. Human circulating eosinophils secrete macrophage migration inhibito- ry factor (MIF): potential role in asthma. J Clin Invest 1998;101:2869-2874.

10. Daryadel A, Grifone RF, Simon HU, Yousefi S. Apoptotic neutrophils release macrophage migration inhibitory factor upon stimulation with tumor necrosis factor-alpha. J Biol Chem 2006;281:27653-27661.

11. Imamura K, Nishihira J, Suzuki M, et al. Identification and immunohistochemical localization of macrophage migration inhibitory factor in human kidney. Biochem Mol Biol Int 1996;40:1233-1242.

12. Shimizu T. Role of macrophage migration inhibitory factor (MIF) in the skin. J Dermatol Sci 2005;37:65-73.

13. Nishihira J, Koyama Y, Mizue Y. Identification of macrophage migration inhibitory factor (MIF) in human vascular endothelial cells and its induction by lipopolysaccharide. Cytokine 1998;10:199-205.

14. Verschuren L, Lindeman JH, van Bockel JH, Abdul-Hussien H, Kooistra T, Kleemann R. Up-regulation and coexpression of MIF and matrix metalloproteinases in human abdominal aortic aneurysms. Antioxid Redox Signal 2005;7:1195-1202.

15. Bernhagen J, Krohn R, Lue H, et al. MIF is a noncognate ligand of CXC chemokine receptors in inflammatory and atherogenic cell recruitment. Nat Med 2007;13:587-596.

16. Mitchell RA, Metz CN, Peng T, Bucala R. Sustained mitogen-activated protein kinase (MAPK) and cytoplasmic phospholipase A2 activation by macrophage migration inhibitory factor (MIF): regulatory role in cell proliferation and glucocorticoid action. J Biol Chem 1999;274:18100-18106.

17. Calandra T, Roger T. Macrophage migration inhibitory factor: a regulator of innate immunity. Nat Rev Immunol 2003;3:791-800.

18. Calandra T, Bernhagen J, Metz CN, et al. MIF as a glucocorticoid-induced modulator of cytokine production. Nature 1995;377:68-71.

19. Mitchell RA, Liao H, Chesney J, et al. Macrophage migration inhibitory factor (MIF) sustains macrophage proinflammatory function by inhibiting p53: regulatory role in the innate immune response. Proc Natl Acad Sci U S A 2002;99:345-350.

20. de Jong YP, Abadia-Molina AC, Satoskar AR, et al. Development of chronic colitis is dependent on the cytokine MIF. Nat Immunol 2001;2:1061-1066.

21. Niino M, Ogata A, Kikuchi S, Tashiro K, Nishihira J. Macrophage migration inhibitory factor in the cerebrospinal 
fluid of patients with conventional and optic-spinal forms of multiple sclerosis and neuro-Behcet's disease. J Neurol Sci 2000;179(Suppl 1-2):127-131.

22. Denkinger CM, Denkinger M, Kort JJ, Metz C, Forsthuber TG. In vivo blockade of macrophage migration inhibitory factor ameliorates acute experimental autoimmune encephalomyelitis by impairing the homing of encephalitogenic T cells to the central nervous system. J Immunol 2003;170:1274-1282.

23. Foote A, Briganti EM, Kipen Y, Santos L, Leech M, Morand EF. Macrophage migration inhibitory factor in systemic lupus erythematosus. J Rheumatol 2004;31:268-273.

24. Sreih A, Ezzeddine R, Leng L, et al. Dual effect of the macrophage migration inhibitory factor gene on the development and severity of human systemic lupus erythematosus. Arthritis Rheum 2011;63:3942-3951.

25. Boyce NW, Tipping PG, Holdsworth SR. Lymphokine (MIF) production by glomerular T-lymphocytes in experimental glomerulonephritis. Kidney Int 1986;30:673-677.

26. Lan HY, Yang N, Nikolic-Paterson DJ, et al. Expression of macrophage migration inhibitory factor in human glomerulonephritis. Kidney Int 2000;57:499-509.

27. Steinhoff M, Meinhardt A, Steinhoff A, Gemsa D, Bucala R, Bacher M. Evidence for a role of macrophage migration inhibitory factor in psoriatic skin disease. Br J Dermatol 1999;141:1061-1066.

28. Shimizu T, Nishihira J, Mizue Y, et al. High macrophage migration inhibitory factor (MIF) serum levels associated with extended psoriasis. J Invest Dermatol 2001;116:989990.

29. Meazza C, Travaglino P, Pignatti P, et al. Macrophage migration inhibitory factor in patients with juvenile idiopathic arthritis. Arthritis Rheum 2002;46:232-237.

30. Wakabayashi K, Otsuka K, Sato M, et al. Elevated serum levels of macrophage migration inhibitory factor and their significant correlation with rheumatoid vasculitis disease activity. Mod Rheumatol 2012;22:59-65.

31. Kim HR, Park MK, Cho ML, et al. Induction of macrophage migration inhibitory factor in ConA-stimulated rheumatoid arthritis synovial fibroblasts through the $\mathrm{P}_{3} 8$ map kinase-dependent signaling pathway. Korean J Intern Med 2010;25:317-326.

32. Llamas-Covarrubias MA, Valle Y, Navarro-Hernandez RE, et al. Serum levels of macrophage migration inhibitory factor are associated with rheumatoid arthritis course. Rheumatol Int 2012;32:2307-2311.
33. Onodera S, Tanji H, Suzuki K, et al. High expression of macrophage migration inhibitory factor in the synovial tissues of rheumatoid joints. Cytokine 1999;11:163-167.

34. Kim HR, Park MK, Cho ML, et al. Macrophage migration inhibitory factor upregulates angiogenic factors and correlates with clinical measures in rheumatoid arthritis. J Rheumatol 2007;34:927-936.

35. Onodera S, Kaneda K, Mizue Y, Koyama Y, Fujinaga M, Nishihira J. Macrophage migration inhibitory factor up-regulates expression of matrix metalloproteinases in synovial fibroblasts of rheumatoid arthritis. J Biol Chem 2000;275:444-450.

36. Onodera S, Nishihira J, Iwabuchi K, et al. Macrophage migration inhibitory factor up-regulates matrix metalloproteinase-9 and -13 in rat osteoblasts. Relevance to intracellular signaling pathways. J Biol Chem 2002;277:78657874 .

37. Vincenti MP, White LA, Schroen DJ, Benbow U, Brinckerhoff CE. Regulating expression of the gene for matrix metalloproteinase-1 (collagenase): mechanisms that control enzyme activity, transcription, and mRNA stability. Crit Rev Eukaryot Gene Expr 1996;6:391-411.

38. Chauchereau A, Georgiakaki M, Perrin-Wolff M, Milgrom $\mathrm{E}$, Loosfelt $\mathrm{H}$. JAB1 interacts with both the progesterone receptor and SRC-1. J Biol Chem 2000;275:8540-8548.

39. Eichbaum QG, Iyer R, Raveh DP, Mathieu C, Ezekowitz RA. Restriction of interferon gamma responsiveness and basal expression of the myeloid human Fc gamma Rıb gene is mediated by a functional PU.1 site and a transcription initiator consensus. J Exp Med 1994;179:19851996.

40. Santos L, Hall P, Metz C, Bucala R, Morand EF. Role of macrophage migration inhibitory factor (MIF) in murine antigen-induced arthritis: interaction with glucocorticoids. Clin Exp Immunol 2001;123:309-314.

41. Leech M, Lacey D, Xue JR, et al. Regulation of p53 by macrophage migration inhibitory factor in inflammatory arthritis. Arthritis Rheum 2003;48:1881-1889.

42. Lacey D, Sampey A, Mitchell R, et al. Control of fibroblast-like synoviocyte proliferation by macrophage migration inhibitory factor. Arthritis Rheum 2003;48:103109.

43. Roger T, David J, Glauser MP, Calandra T. MIF regulates innate immune responses through modulation of Tolllike receptor 4. Nature 2001;414:920-924.

44. Onodera S, Suzuki K, Matsuno T, Kaneda K, Takagi M, 
Nishihira J. Macrophage migration inhibitory factor induces phagocytosis of foreign particles by macrophages in autocrine and paracrine fashion. Immunology 1997;92:131-137.

45. Leech M, Metz C, Hall P, et al. Macrophage migration inhibitory factor in rheumatoid arthritis: evidence of proinflammatory function and regulation by glucocorticoids. Arthritis Rheum 1999;42:1601-1608.

46. Toh ML, Aeberli D, Lacey D, et al. Regulation of IL-1 and TNF receptor expression and function by endogenous macrophage migration inhibitory factor. J Immunol 2006;177:4818-4825.

47. Herenius MM, Oliveira AS, Wijbrandts CA, Gerlag DM, Tak PP, Lebre MC. Anti-TNF therapy reduces serum levels of chemerin in rheumatoid arthritis: a new mechanism by which anti-TNF might reduce inflammation. PLoS One 2013;8:e57802.

48. Loppnow H, Libby P. Adult human vascular endothelial cells express the IL6 gene differentially in response to LPS or IL1. Cell Immunol 1989;122:493-503.

49. O'Shea F, Salonen D, Inman R. The challenge of early diagnosis in ankylosing spondylitis. J Rheumatol 2007;34:57 .

50. Kim HR, Kim KW, Jung HG, et al. Macrophage migration inhibitory factor enhances osteoclastogenesis through upregulation of RANKL expression from fibroblast-like synoviocytes in patients with rheumatoid arthritis. Arthritis Res Ther 2011;13:R43.

51. Liu R, Xu N, Wang X, et al. Influence of MIF, CD4O, and CD226 polymorphisms on risk of rheumatoid arthritis. Mol Biol Rep 2012;39:6915-6922.

52. Llamas-Covarrubias MA, Valle Y, Bucala R, et al. Macrophage migration inhibitory factor (MIF): genetic evidence for participation in early onset and early stage rheumatoid arthritis. Cytokine 2013;61:759-765.

53. Bucala R. Signal transduction: a most interesting factor. Nature 2000;408:146-147.

54. Leng L, Metz CN, Fang Y, et al. MIF signal transduction initiated by binding to CD74. J Exp Med 2003;197:14671476.

55. Firestein GS, Manning AM. Signal transduction and transcription factors in rheumatic disease. Arthritis Rheum 1999;42:609-621.

56. Kyriakis JM, Avruch J. Protein kinase cascades activated by stress and inflammatory cytokines. Bioessays 1996;18:567-577.
57. Santos LL, Lacey D, Yang Y, Leech M, Morand EF. Activation of synovial cell p38 MAP kinase by macrophage migration inhibitory factor. J Rheumatol 2004;31:1038-1043.

58. Ren Y, Chan HM, Li Z, et al. Upregulation of macrophage migration inhibitory factor contributes to induced $\mathrm{N}-\mathrm{Myc}$ expression by the activation of ERK signaling pathway and increased expression of interleukin-8 and VEGF in neuroblastoma. Oncogene 2004;23:4146-4154.

59. Sun B, Nishihira J, Suzuki M, et al. Induction of macrophage migration inhibitory factor by lysophosphatidic acid: relevance to tumor growth and angiogenesis. Int J Mol Med 2003;12:633-641.

6o. Watanabe H, Shimizu T, Nishihira J, et al. Ultraviolet A-induced production of matrix metalloproteinase-1 is mediated by macrophage migration inhibitory factor (MIF) in human dermal fibroblasts. J Biol Chem 2004;279:1676-1683.

61. Amin MA, Volpert OV, Woods JM, Kumar P, Harlow LA, Koch AE. Migration inhibitory factor mediates angiogenesis via mitogen-activated protein kinase and phosphatidylinositol kinase. Circ Res 2003;93:321-329.

62. Kleemann R, Grell M, Mischke R, Zimmermann G, Bernhagen J. Receptor binding and cellular uptake studies of macrophage migration inhibitory factor (MIF): use of biologically active labeled MIF derivatives. J Interferon Cytokine Res 2002;22:351-363.

63. Bernhagen J, Mitchell RA, Calandra T, Voelter W, Cerami A, Bucala R. Purification, bioactivity, and secondary structure analysis of mouse and human macrophage migration inhibitory factor (MIF). Biochemistry 1994;33:1414414155.

64. Stavitsky AB, Xianli J. In vitro and in vivo regulation by macrophage migration inhibitory factor (MIF) of expression of MHC-II, costimulatory, adhesion, receptor, and cytokine molecules. Cell Immunol 2002;217:95-104.

65. Mikulowska A, Metz CN, Bucala R, Holmdahl R. Macrophage migration inhibitory factor is involved in the pathogenesis of collagen type II-induced arthritis in mice. J Immunol 1997;158:5514-5517.

66. Leech M, Metz C, Santos L, et al. Involvement of macrophage migration inhibitory factor in the evolution of rat adjuvant arthritis. Arthritis Rheum 1998;41:910-917.

67. Leech M, Metz C, Bucala R, Morand EF. Regulation of macrophage migration inhibitory factor by endogenous glucocorticoids in rat adjuvant-induced arthritis. Arthritis Rheum 2000;43:827-833. 
68. Ichiyama H, Onodera S, Nishihira J, et al. Inhibition of joint inflammation and destruction induced by anti-type II collagen antibody/lipopolysaccharide (LPS)-induced arthritis in mice due to deletion of macrophage migration inhibitory factor (MIF). Cytokine 2004;26:187-194.

69. Gregory JL, Leech MT, David JR, Yang YH, Dacumos A, Hickey MJ. Reduced leukocyte-endothelial cell interactions in the inflamed microcirculation of macrophage migration inhibitory factor-deficient mice. Arthritis Rheum 2004;50:3023-3034.

70. Bresnihan B, Alvaro-Gracia JM, Cobby M, et al. Treatment of rheumatoid arthritis with recombinant human interleukin-1 receptor antagonist. Arthritis Rheum 1998;41:2196-2204.
71. Moreland LW, Schiff MH, Baumgartner SW, et al. Etanercept therapy in rheumatoid arthritis: a randomized, controlled trial. Ann Intern Med 1999;130:478-486.

72. Targan SR, Hanauer SB, van Deventer SJ, et al. A shortterm study of chimeric monoclonal antibody cA2 to tumor necrosis factor alpha for Crohn's disease. Crohn's Disease cA2 Study Group. N Engl J Med 1997;337:10291035 .

73. Maini R, St Clair EW, Breedveld F, et al. Infliximab (chimeric anti-tumour necrosis factor alpha monoclonal antibody) versus placebo in rheumatoid arthritis patients receiving concomitant methotrexate: a randomised phase III trial. ATTRACT Study Group. Lancet 1999;354:19321939. 